AIDS Care

Psychological and Socio-medical Aspects of AIDS/HIV

ISSN: 0954-0121 (Print) 1360-0451 (Online) Journal homepage: http://www.tandfonline.com/loi/caic20

\title{
Correlates of HIV infection among patients with mental illness in Brazil
}

\section{Mark D.C. Guimarães, Karen McKinnon, Francine Cournos, Carla J. Machado, Ana Paula S. Melo, Lorenza N. Campos \& Milton L. Wainberg}

To cite this article: Mark D.C. Guimarães, Karen McKinnon, Francine Cournos, Carla J. Machado, Ana Paula S. Melo, Lorenza N. Campos \& Milton L. Wainberg (2014) Correlates of HIV infection among patients with mental illness in Brazil, AIDS Care, 26:4, 505-513, DOI: 10.1080/09540121.2013.832722

To link to this article: http://dx.doi.org/10.1080/09540121.2013.832722

册 Published online: 02 Sep 2013.

Submit your article to this journal $[\pi$

Щ Article views: 161

Q View related articles ¿

View Crossmark data ־

4 Citing articles: 1 View citing articles 


\title{
Correlates of HIV infection among patients with mental illness in Brazil
}

\author{
Mark D.C. Guimarães ${ }^{\mathrm{a} *}$, Karen McKinnon ${ }^{\mathrm{b}}$, Francine Cournos $^{\mathrm{c}}$, Carla J. Machado ${ }^{\mathrm{a}}$, Ana Paula S. Melo, \\ Lorenza N. Campos ${ }^{\mathrm{a}, \mathrm{e}}$ and Milton L. Wainberg ${ }^{\mathrm{f}}$ \\ ${ }^{a}$ Department of Preventive and Social Medicine, School of Medicine, Federal University of Minas Gerais, Belo Horizonte, Brazil; \\ ${ }^{\mathrm{b}}$ New York State Psychiatric Institute, Columbia University College of Physicians and Surgeons, Manhattan, NY, USA; ${ }^{\mathrm{c} D e p a r t m e n t}$ \\ of Epidemiology, Mailman School of Public Health, Columbia University, New York, NY, USA; ${ }^{\mathrm{d}}$ School of Medicine, Federal \\ University of São João Del-Rei, Divinópolis, Brazil; ${ }^{\mathrm{e}}$ Minas Gerais State Health Department, Eduardo de Menezes Hospital, Belo \\ Horizonte, Brazil; ' Department of Psychiatry, Columbia University, New York, NY, USA
}

(Received 23 January 2013; final version received 4 August 2013)

\begin{abstract}
People living with mental illness are at increased risk for HIV. There are scarce data on correlates and prevalence of HIV infection, and none with a nationally representative sample. We report on correlates of HIV infection from a crosssectional national sample of adults receiving care in 26 publicly funded mental health treatment settings throughout Brazil. Weighted prevalence rate ratios were obtained using multiple log-binomial regression modeling. History of homelessness, ever having an STD, early age of first sexual intercourse before 18 years old, having suffered sexual violence, previous HIV testing, self-perception of high risk of HIV infection and not knowing one's risk were statistically associated with HIV infection. Our study found an elevated HIV seroprevalence and correlates of infection were not found to include psychiatric diagnoses or hospitalizations but instead reflected marginalized living circumstances and HIV testing history. These adverse life circumstances (history of homelessness, having suffered sexual violence, reporting a sexually transmitted disease, and early sexual debut) may not be unique to people living with mental illness but nonetheless the mental health care system can serve as an important point of entry for HIV prevention in this population.
\end{abstract}

Keywords: HIV prevalence; correlates of HIV infection; mental illness; risk behavior; Brazil; multicenter study

\section{Introduction}

Despite advances in prevention and treatment, human immunodeficiency virus (HIV) continues to affect the general population and more vulnerable subgroups worldwide (Vermund, 2011). There is consistent evidence that individuals with mental illness are at increased risk of sexually transmitted diseases (STDs), including HIV (Angelino, 2008; Carey, Ravi, Chandra, Desai, \& Neal, 2007; Guimarães et al., 2009; Meade \& Sikkema, 2007; Pirl, Greer, Weissgarber, Liverant, \& Safren, 2005; Rosenberg et al., 2001), yet people with mental illness remain an understudied subgroup in the AIDS epidemic (Ngwena, 2011), creating an evidence vacuum from which to plan targeted interventions at the individual or health systems levels.

Correlates of HIV infection among people living with mental illness include gender, age, marital status, race-ethnicity, childhood sexual and non-sexual abuse, sexual and domestic violence, homelessness, type of psychiatric care received, severe mental illness (SMI), and substance use - both parenteral and non-parenteral (Carey et al., 2007; Collins, Holman, Freeman, \& Patel, 2006; Cournos \& McKinnon, 1997; Cournos et al., 1991; Himelhoch et al., 2007; Prince, Walkup,
Akincigil, Amin, \& Crystal, 2012; Rosenberg et al., 2001). However, studies are inconclusive due to small samples, lack of representativeness and other sampling biases, as well as difficulty in discerning the intricate relationships among the many potential explanatory variables. For instance, a recent longitudinal study among Puerto Rican women found a strong association between substance use, HIV infection, and mental disease (Loue, Sajatovic, \& Mendez, 2011), though this study's sample size prevents disentangling complex associative relationships. In a study of Medicaid beneficiaries in eight US states, a substance use disorder (SUD) rather than diagnoses characterized as SMI was the main factor associated with new HIV diagnosis (Prince et al., 2012). Though the sample size was large, the findings were based solely on patients referred for HIV testing rather than on a representative sample of patients with SMI, and the authors were not able to adjust for risk behaviors (e.g., sexual risk, illicit drug and alcohol use, number of partners), important study design constraints which limit the usefulness of its findings for public health planning (Cournos, Guimarães, \& Wainberg, 2012).

Brazil is one of the few low- or middle-income countries to focus significant resources on its psychiatric

\footnotetext{
*Corresponding author. Email: mark.guimaraes@gmail.com 
population. Rates of syphilis, hepatitis B and C, and HIV were shown to be higher among patients in psychiatric treatment than estimates for the general adult Brazilian population (Guimarães et al., 2009). High rates of unprotected sex, substance use, early sexual initiation, history of incarceration and homelessness, low HIV testing rates, and poor HIV/AIDS knowledge all were found in a representative sample of individuals living with mental illness under care throughout Brazil (Guimarães, McKinnon, Campos, Melo, \& Wainberg, 2010; Melo et al., 2010; Melo, Machado, \& Guimarães, 2011). In a smaller study of patients with mental illness in Rio de Janeiro, which has among the highest AIDS case rates in the country (Brazil, Ministerio da Saúde, 2011), $42 \%$ of 98 patients engaged in vaginal or anal sex within the past three months; comorbid substance use disorder was significantly associated with sexual activity; only $22 \%$ of sexually active patients used condoms consistently, despite having better HIV knowledge than those who were sexually abstinent; $45 \%$ of patients reported not engaging in any HIV protective behaviors; and there were no reports of drug injection (Wainberg et al., 2008).

Most studies of psychiatric populations have been undertaken in high-income countries among patients with SMI or in mental health care facilities with an overrepresentation of SMI conditions. Thus, seroprevalence and behavioral correlates may be overestimated or lack representativeness, and precise measurement of prevalence is needed. Furthermore, studies of determinants of HIV seroprevalence among patients with a wider range of psychiatric conditions in both inpatient and outpatient care are still needed. The aim of the present study was to examine the association between HIV infection and sociodemographic, clinical, and risk behavior characteristics in a representative sample of adults living with mental illness in Brazil.

\section{Methods}

To examine correlates of HIV infection, we analyzed data obtained in a national cross-sectional study designed to estimate the seroprevalence of HIV, syphilis, and hepatitis $\mathrm{B}$ and $\mathrm{C}$ and to assess risk behaviors among adults (18 years or older) with mental illness under care in Brazil, previously described (Guimarães et al., 2009). Briefly, the study was conducted in 11 public psychiatric hospitals and 15 public mental health outpatient clinics, named Psychosocial Care Centers (CAPS) in 2006. Sample size was proportional to type of care (hospital or CAPS) and distribution of AIDS cases in the five main Brazilian regions. Two-stage probability sampling was used to select centers and individuals within each center. Only patients capable of providing written informed consent and of answering the questionnaire were included in the study. Inpatients recently admitted were contacted after a minimum seven-day period of hospitalization to allow for clinical stabilization. Recruitment and interviews occurred during the same onemonth period for all centers. Clinics treating primary SUDs were excluded so as not to overestimate selected risk behaviors and/or prevalence rates. Ethical approval was obtained from each site, the Federal University of Minas Gerais (UFMG/ETIC 125/03) and the National Ethical Review Board (CONEP 592/2006). Written informed consent was obtained.

\section{Exposure and event measurements}

The event of interest in this analysis was HIV positivity. Blood samples for serology were collected using standard procedures, including pretest counseling, and processed and checked for quality control (Guimarães et al., 2009). HIV positivity was assessed by ELISA for AntiHIV 1 and 2 and confirmed by Western Blot. Research staff members returned results to patients in each participating site following posttest counseling procedures. Patients who were positive were referred for medical care and follow-up.

A semistructured questionnaire was used by experienced and trained mental health care providers who conducted person-to-person interviews. The study protocol, questionnaires, and procedures were tested in a pilot study (Guimarães et al., 2008). Explanatory characteristics investigated included sociodemographic information, psychiatric conditions, and risk behaviors. Psychiatric diagnoses, established by psychiatrists, were obtained from medical charts and were grouped according to the International Statistical Classification of Diseases and Related Health Problems, 10th edition, (World Health Organization (WHO), 2004). When more than one psychiatric diagnosis was present, these were recorded hierarchically according to clinical severity as follows: (1) schizophrenia and other psychotic disorders, (2) bipolar disorder, (3) depression with psychotic symptoms, (4) depression, (5) anxiety, (6) substance use disorder, and (7) others. Because of small numbers, categories (1), (2), and (3) were grouped together as SMI and the remaining diagnoses were categorized as nonSMI. History of STDs was elicited by self-report regarding whether health professionals had ever informed patients that they had any STD. HIV knowledge was measured by a score rated on a 0-1 scale using 10 statements regarding HIV transmission and prevention; median value of correct answers was defined as the cut-off point (Melo et al., 2010). Current place of residence was defined as unstable (living in shelters, hostels, streets, rooms) and stable (living in houses or apartments), and unsafe sex was defined as not always using condoms. 


\section{Data analysis}

Descriptive analysis was carried out and the chi-square test was performed for the analysis of categorical data. HIV-positive participants were compared to HIV-negative participants and the magnitude of the associations was estimated by the weighted prevalence rate ratio $\left(\mathrm{PRR}_{\mathrm{w}}\right)$ with 95\% confidence intervals using log-binomial regression for both univariate and multivariate analyses. Log-binomial method is based on the binomial distribution and it is an efficient way of obtaining prevalence rate ratios in cross-sectional studies (Petersen \& Deddens, 2008). These estimates were proportionally weighted by the sample size of each site relative to its total population, i.e., number of beds or number of registered patients, considering the potential within-cluster correlation. All variables with $p$-values equal to or less than 0.20 obtained in the univariate analysis were used to start multivariate modeling. A backward deletion strategy was applied and only those variables with $p$-values equal to or less than 0.05 remained in final multivariate model. All analyses were carried out using $\mathrm{SAS}^{\circledR}$ (Spiegelman \& Hertzmark, 2005).

\section{Results}

The final sample for this analysis consisted of 2237 patients who had both interviews and blood collected. Reasons for non-participation were mostly due to refusals $(52 \%)$ and not being located $(19 \%)$. There was no difference between participants and non-participants with regard to schooling, age, gender, or psychiatric diagnosis. However, hospital patients had a higher participation rate as compared to CAPS patients $(p<0.01)$.

Descriptive characteristics are shown in Table 1. Overall, most were recruited in CAPS, had SMI, and had at least one prior psychiatric hospitalization, but there was a low proportion of substance use as primary psychiatric diagnosis $(7 \%)$. We should note the high proportion of markers of vulnerability to HIV in this population, including history of homelessness, incarceration, violence, STDs, substance use, and ever practicing unsafe sex. However, only 3\% reported injection drug use ever. Also, most had never been tested for HIV despite the high proportion of self-perception of being at high risk or not knowing one's risk for HIV. In this sample, $0.7 \%$ were found to be HIV positive (Table 1). The univariate analysis showed that the following factors were statistically associated with HIV infection (Table 2): schooling at or above 5 years, current unstable housing, history of homelessness and STDs, previous HIV testing, age of first sexual intercourse before 18 years old, use of alcohol or drugs during sexual intercourse, partner's refusal to use condoms, condom use at last sexual intercourse, money/drugs exchanged for sex, more than one sexual partner ever, selfperception risk of HIV (both high and not knowing one's risk), ever use of alcohol and illicit drug, and having suffered verbal or sexual violence (Table 2).

The multivariate analysis (Table 3) indicated six factors remaining associated with HIV infection $(p<$ 0.05 ): history of homelessness, history of STDs, age at first sexual intercourse before 18 years old, having suffered sexual violence, previous HIV testing, and self-perception risk of HIV (both high and not knowing one's risk).

\section{Discussion}

This is the first representative study to examine factors associated with HIV infection among patients with mental illness. Our results indicate that life circumstances (history of homelessness, having suffered sexual violence, reporting a sexually transmitted disease, and early sexual debut) are more robust independent correlates of HIV infection than psychiatric factors among people receiving treatment for a psychiatric condition in Brazil. The low proportion of injection drug users (3\%) and SUD as a primary psychiatric diagnosis (7\%), the absence of HIV infection in either group, and the lack of association between psychiatric diagnoses and prior hospitalization with HIV infection in our analysis reinforce this hypothesis, and provide evidence of high sexual risk for HIV among adults in psychiatric treatment in Brazil. Similar results have been found in India (Carey et al., 2007), South Africa (Henning, Krüger, \& Fletcher, 2012), and Brazil (Wainberg et al., 2008), and they are consistent with the distribution of risk categories of reported AIDS cases in Brazil $(68.7 \%$ and $15.5 \%$ are sexually or injection drug use related, respectively) (Brazil, Ministério da Saúde, 2011). Our findings are also consistent with prior studies in the USA (Carey, Carey, Maisto, Gordon, \& Vanable, 2001; Cournos \& McKinnon, 1997; Himelhoch et al., 2007; Prince et al., 2012; Rosenberg et al., 2001), with the exception of younger age at first sexual intercourse, a factor that has not been systematically addressed in prior studies.

A striking finding was that HIV infection was nine times as likely among patients with sexual debut prior to age 18 compared to those with later debut. A nationally representative household survey in Brazil found that $61.6 \%$ of youth aged $16-19$ had already had sex, and the average debut age was 14.9 years (Paiva, Calazans, Venturi, \& Dias, 2008), whereas for youth in the US debut was 17.6 years (Santelli, Lindberg, Abma, McNeely, \& Resnick, 2000). Given that in Brazil condom use is significantly lower among youth who are poor, minorities, and not-in-school (Paiva et al., 2008), the need to address youth in these circumstances with HIV prevention is urgent, including the provision of 
Table 1. Descriptive analysis of selected variables, PESSOAS project 2006-2007 $(n=2237)$.

\begin{tabular}{|c|c|}
\hline Characteristics & $n(\%)$ \\
\hline \multicolumn{2}{|l|}{ Gender } \\
\hline Male & $1076(48.1)$ \\
\hline Female & $1161(51.9)$ \\
\hline \multicolumn{2}{|l|}{ Age (years old) } \\
\hline $18-39$ & $994(44.4)$ \\
\hline$>40$ & $1243(55.6)$ \\
\hline \multicolumn{2}{|l|}{ Skin color } \\
\hline White & $1146(51.2)$ \\
\hline Non-white & $1091(48.2)$ \\
\hline \multicolumn{2}{|l|}{ Marital status } \\
\hline Single & $1490(66.6)$ \\
\hline Married/in union & $747(33.4)$ \\
\hline \multicolumn{2}{|c|}{ Knows how to read and to write } \\
\hline Yes & $1818(81.5)$ \\
\hline No & $414(18.5)$ \\
\hline \multicolumn{2}{|l|}{ Schooling (years) } \\
\hline$\geq 5$ & $1110(49.6)$ \\
\hline$<5$ & $1127(50.4)$ \\
\hline \multicolumn{2}{|l|}{ Place of residence } \\
\hline Unstable & $280(12.5)$ \\
\hline Stable & $1957(87.5)$ \\
\hline \multicolumn{2}{|c|}{ History of homelessness } \\
\hline No & $1834(82.0)$ \\
\hline Yes & $403(18.0)$ \\
\hline \multicolumn{2}{|c|}{ Type of center of recruitment } \\
\hline CAPS & $1437(64.2)$ \\
\hline Hospital & $800(35.8)$ \\
\hline \multicolumn{2}{|c|}{ Prior psychiatric hospitalization } \\
\hline No & $933(41.9)$ \\
\hline Yes & $1296(58.1)$ \\
\hline \multicolumn{2}{|c|}{ Main psychiatric diagnosis } \\
\hline Non-SMI & $969(43.7)$ \\
\hline SMI & $1268(56.7)$ \\
\hline \multicolumn{2}{|l|}{ History of STDs } \\
\hline No & $1676(76.0)$ \\
\hline Yes & $530(24.0)$ \\
\hline \multicolumn{2}{|l|}{ Previous HIV testing } \\
\hline No & $1635(73.0)$ \\
\hline Yes & $602(27.0)$ \\
\hline \multicolumn{2}{|c|}{ Age of first sexual intercourse (years old) } \\
\hline$\geq 18$ & $801(42.7)$ \\
\hline$<18$ & $1076(57.3)$ \\
\hline \multicolumn{2}{|c|}{ Alcohol/drug use during sexual intercourse } \\
\hline No & $1625(73.1)$ \\
\hline Yes & $597(26.9)$ \\
\hline \multicolumn{2}{|c|}{ Partner's refusal in using condoms } \\
\hline No & $1377(72.1)$ \\
\hline Yes & $534(27.9)$ \\
\hline \multicolumn{2}{|c|}{ Condom use in the last sexual intercourse } \\
\hline No & $1393(74.6)$ \\
\hline Yes & $473(25.4)$ \\
\hline \multicolumn{2}{|c|}{ Money/drugs exchange for sex } \\
\hline No & $1635(73.5)$ \\
\hline Yes & $589(26.5)$ \\
\hline
\end{tabular}

Table 1. (Continued)

\begin{tabular}{|c|c|}
\hline Characteristics & $n(\%)$ \\
\hline \multicolumn{2}{|c|}{ Number of sexual partners (ever) } \\
\hline$>1$ & $1380(65.3)$ \\
\hline$\leq 1$ & $732(34.7)$ \\
\hline \multicolumn{2}{|l|}{ HIV knowledge } \\
\hline Good & $1210(54.6)$ \\
\hline Poor & $1006(45.4)$ \\
\hline \multicolumn{2}{|c|}{ Self-perceived risk of HIV } \\
\hline Did not know & $647(28.9)$ \\
\hline Low & $1191(53.2)$ \\
\hline High & $399(17.8)$ \\
\hline \multicolumn{2}{|c|}{ History of incarceration } \\
\hline No & $1668(74.6)$ \\
\hline Yes & $569(25.4)$ \\
\hline \multicolumn{2}{|c|}{ Illicit drug use (ever) } \\
\hline No & $1683(75.2)$ \\
\hline Yes & $554(24.8)$ \\
\hline \multicolumn{2}{|c|}{ Injection drug use (ever) } \\
\hline No & $2159(97.0)$ \\
\hline Yes & $66(3.0)$ \\
\hline \multicolumn{2}{|c|}{ Tobacco use (ever) } \\
\hline No & $639(28.7)$ \\
\hline Yes & $1587(71.3)$ \\
\hline \multicolumn{2}{|l|}{ Alcohol use (ever) } \\
\hline No & $804(35.9)$ \\
\hline Yes & $1433(64.1)$ \\
\hline \multicolumn{2}{|l|}{ Verbal violence } \\
\hline No & $688(30.8)$ \\
\hline Yes & $1545(69.2)$ \\
\hline \multicolumn{2}{|l|}{ Physical violence } \\
\hline No & $938(42.0)$ \\
\hline Yes & $1293(58.0)$ \\
\hline \multicolumn{2}{|l|}{ Sexual violence } \\
\hline No & $1783(80.0)$ \\
\hline Yes & $442(20.0)$ \\
\hline \multicolumn{2}{|c|}{ Practiced unsafe sex (ever) } \\
\hline No & $428(19.4)$ \\
\hline Yes & $1778(80.6)$ \\
\hline \multicolumn{2}{|l|}{ Anti-HIV } \\
\hline Negative & $2222(99.3)$ \\
\hline Positive & $15(0.7)$ \\
\hline
\end{tabular}

Notes: CAPS, psychosocial care center; SMI, schizophrenia, bipolar disorders, depression with psychotic symptoms.

HIV prevention services to adolescents with mental health disorders within the public health system of care or the public school system.

History of homelessness was strongly associated with HIV, with a three-fold increased risk compared to those who had never been homeless. Of note, $18 \%$ of the sample had been homeless as compared to estimates of $0.6-1.0 \%$ among the general population in Brazil (Direitos Humanos, 2005). As elsewhere, in Brazil high rates of homelessness have followed recent deinstitutionalization. With deinstitutionalization, community-based 
Table 2. Univariate analysis of HIV seroprevalence, PESSOAS project 2006-2007 $(n=2237)$.

\begin{tabular}{|c|c|c|c|c|c|}
\hline Characteristics & $N$ & $n(\%)$ & $(\%)_{\mathrm{W}}$ & $\mathrm{PRR}_{\mathrm{W}}(95 \% \mathrm{CI})$ & $\chi^{2}(p$-value $)$ \\
\hline \multicolumn{6}{|l|}{ Gender } \\
\hline Male & 1076 & $7(0.65)$ & $(0.43)$ & $1.14(0.53-2.42)$ & \\
\hline Female & 1161 & $8(0.69)$ & $(0.38)$ & 1.0 & $0.11(0.74)$ \\
\hline \multicolumn{6}{|l|}{ Age (years old) } \\
\hline $18-39$ & 995 & $7(0.70)$ & $(0.52)$ & $1.50(0.71-3.17)$ & \\
\hline$\geq 40$ & 1243 & $8(0.64)$ & $(0.34)$ & 1.0 & $1.10(0.29)$ \\
\hline \multicolumn{6}{|l|}{ Skin color } \\
\hline White & 1147 & $7(0.61)$ & $(0.41)$ & 1.0 & \\
\hline Non-Black & 1091 & $8(0.73)$ & $(0.41)$ & $0.99(0.47-2.09)$ & $0.00(0.98)$ \\
\hline \multicolumn{6}{|l|}{ Marital status } \\
\hline Single & 1491 & $13(0.87)$ & $(0.47)$ & $1.85(0.68-5.05)$ & \\
\hline Married/in union & 747 & $2(0.27)$ & $(0.25)$ & 1.0 & $1.46(0.23)$ \\
\hline \multicolumn{6}{|c|}{ Knows how to read/write } \\
\hline Yes & 1824 & $13(0.71)$ & $(0.46)$ & $1.87(0.61-5.71)$ & \\
\hline No & 414 & $2(0.48)$ & $(0.24)$ & 1.0 & $1.19(0.27)$ \\
\hline \multicolumn{6}{|l|}{ Schooling (years) } \\
\hline$\geq 5$ & 1111 & $10(0.90)$ & $(0.60)$ & 1.0 & \\
\hline$<5$ & 1127 & $5(0.44)$ & $(0.26)$ & $0.43(0.20-0.94)$ & $4.45(0.03)$ \\
\hline \multicolumn{6}{|l|}{ Place of residence } \\
\hline Unstable & 291 & $2(0.69)$ & $(0.53)$ & $3.38(1.09-10.5)$ & \\
\hline Stable & 1947 & $13(0.67)$ & $(0.16)$ & 1.0 & $4.42(0.03)$ \\
\hline \multicolumn{6}{|c|}{ History of homelessness } \\
\hline No & 1835 & $8(0.44)$ & $(0.22)$ & 1.0 & \\
\hline Yes & 403 & $7(1.74)$ & $(1.10)$ & $4.93(2.31-10.5)$ & $17.08(<0.001)$ \\
\hline \multicolumn{6}{|c|}{ Type of center of recruitment } \\
\hline CAPS & 1438 & $7(0.49)$ & $(0.48)$ & 1.0 & \\
\hline Hospital & 800 & $8(1.00)$ & $(0.36)$ & $0.75(0.36-1.60)$ & $0.53(0.47)$ \\
\hline \multicolumn{6}{|c|}{ Prior psychiatric hospitalization } \\
\hline No & 934 & $6(0.64)$ & $(0.37)$ & 1.0 & \\
\hline Yes & 1296 & $9(0.69)$ & $(0.44)$ & $1.19(0.55-2.62)$ & $0.21(0.65)$ \\
\hline \multicolumn{6}{|c|}{ Main psychiatric diagnosis } \\
\hline Non-SMI & 978 & $4(0.41)$ & $(0.31)$ & 1.0 & \\
\hline SMI & 1260 & $11(0.87)$ & $(0.48)$ & $1.55(0.69-3.49)$ & $1.13(0.29)$ \\
\hline \multicolumn{6}{|l|}{ History of STDs } \\
\hline No & 1677 & $6(0.36)$ & $(0.16)$ & 1.0 & \\
\hline Yes & 530 & $9(1.70)$ & $(1.36)$ & $8.24(3.67-18.5)$ & $26.1(<0.001)$ \\
\hline \multicolumn{6}{|l|}{ Previous HIV testing } \\
\hline No & 1635 & $3(0.18)$ & $(0.06)$ & 1.0 & \\
\hline Yes & 603 & $12(1.99)$ & $(1.24)$ & $10.18(4.11-25.2)$ & $25.2(<0.001)$ \\
\hline \multicolumn{6}{|c|}{ Age of first sex (years old) } \\
\hline$\geq 18$ & 802 & $1(0.12)$ & $(0.06)$ & 1.0 & \\
\hline$<18$ & 1081 & $14(1.30)$ & $(0.86)$ & $15.5(2.47-97.3)$ & $8.57(0.003)$ \\
\hline \multicolumn{6}{|c|}{ Alcohol/drug use during sex } \\
\hline No & 1640 & $7(0.43)$ & $(0.91)$ & 1.0 & \\
\hline Yes & 598 & $8(1.34)$ & $(0.23)$ & $3.93(1.82-8.49)$ & $12.14(<0.001)$ \\
\hline \multicolumn{6}{|c|}{ Partner's refusal in using condoms } \\
\hline No & 1377 & $7(0.51)$ & $(0.34)$ & 1.0 & \\
\hline Yes & 535 & $8(1.50)$ & $(0.98)$ & $2.87(1.36-6.09)$ & $7.63(0.006)$ \\
\hline \multicolumn{6}{|c|}{ Condom use in the last sexual intercourse } \\
\hline No & 1393 & $7(0.50)$ & $(0.41)$ & 1.0 & \\
\hline Yes & 474 & $8(1.69)$ & $(0.93)$ & $2.26(1.06-4.84)$ & $4.42(0.04)$ \\
\hline \multicolumn{6}{|c|}{ Money/drug exchange for sex } \\
\hline No & 1649 & $6(0.36)$ & $(0.19)$ & 1.0 & \\
\hline Yes & 589 & $9(1.53)$ & $(0.99)$ & $5.29(2.37-11.79)$ & $16.56(<0.001)$ \\
\hline
\end{tabular}


Table 2. (Continued)

\begin{tabular}{|c|c|c|c|c|c|}
\hline Characteristics & $N$ & $n(\%)$ & $(\%)_{\mathrm{W}}$ & $\mathrm{PRR}_{\mathrm{W}}(95 \% \mathrm{CI})$ & $\chi^{2}(p$-value $)$ \\
\hline \multicolumn{6}{|c|}{ Number of sexual partners (ever) } \\
\hline$\leq 1$ & 732 & $2(0.27)$ & $(0.17)$ & 1.0 & \\
\hline$>1$ & 1380 & $12(0.87)$ & $(0.61)$ & $3.63(1.24-10.64)$ & $5.51(0.02)$ \\
\hline \multicolumn{6}{|l|}{ HIV knowledge } \\
\hline Good & 1211 & $9(0.74)$ & $(0.47)$ & 1.0 & \\
\hline Poor & 1006 & $6(0.60)$ & $(0.37)$ & $0.79(0.38-1.69)$ & $0.35(0.55)$ \\
\hline \multicolumn{6}{|c|}{ Self-perceived risk of HIV } \\
\hline Low & 1191 & $4(0.34)$ & $(0.20)$ & 1.0 & \\
\hline Did not know & 647 & $7(1.08)$ & $(0.52)$ & $2.61(1.01-6.76)$ & $9.39(<0.01)$ \\
\hline High & 399 & $4(1.00)$ & $(0.92)$ & $4.68(1.74-12.56)$ & $3.93(0.04)$ \\
\hline \multicolumn{6}{|c|}{ History of incarceration } \\
\hline No & 1669 & $9(0.54)$ & $(0.31)$ & 1 & \\
\hline Yes & 569 & $6(1.05)$ & $(0.65)$ & $2.08(0.98-4.42)$ & $3.65(0.06)$ \\
\hline \multicolumn{6}{|c|}{ Illicit drug use (ever) } \\
\hline No & 1684 & $6(0.36)$ & $(0.19)$ & 1 & \\
\hline Yes & 554 & $9(1.62)$ & $(1.17)$ & $6.21(2.83-13.59)$ & $20.84(<0.001)$ \\
\hline \multicolumn{6}{|c|}{ Injection drug use (ever) } \\
\hline No & 2159 & $15(0.69)$ & $(0.43)$ & - & - \\
\hline Yes & 66 & $0(0.0)$ & $(0.0)$ & & \\
\hline \multicolumn{6}{|c|}{ Tobacco use (ever) } \\
\hline No & 639 & $4(0.63)$ & $(0.36)$ & 1 & \\
\hline Yes & 1588 & $11(0.69)$ & $(0.43)$ & $1.17(0.47-2.93)$ & $0.12(0.73)$ \\
\hline \multicolumn{6}{|c|}{ Alcohol use (ever) } \\
\hline No & 804 & $2(0.25)$ & $(0.15)$ & 1 & \\
\hline Yes & 1434 & $13(0.91)$ & $(0.57)$ & $3.65(1.25-10.67)$ & $5.60(0.02)$ \\
\hline \multicolumn{6}{|l|}{ Verbal violence } \\
\hline No & 688 & $1(0.15)$ & $(0.07)$ & 1 & \\
\hline Yes & 1545 & $14(0.91)$ & $(0.61)$ & $8.79(1.81-42.61)$ & $7.29(0.01)$ \\
\hline \multicolumn{6}{|l|}{ Physical violence } \\
\hline No & 938 & $4(0.43)$ & $(0.24)$ & 1 & \\
\hline Yes & 1294 & $11(0.85)$ & $(0.54)$ & $2.25(0.94-5.39)$ & $3.32(0.07)$ \\
\hline \multicolumn{6}{|l|}{ Sexual violence } \\
\hline No & 1784 & $8(0.45)$ & $(0.23)$ & 1 & \\
\hline Yes & 442 & $7(1.58)$ & $(1.10)$ & $4.72(2.22-10.04)$ & $16.28(<0.001)$ \\
\hline \multicolumn{6}{|c|}{ Practiced unsafe sex (ever) } \\
\hline No & 428 & $2(0.47)$ & $(0.21)$ & 1 & \\
\hline Yes & 1779 & $13(0.73)$ & $(0.48)$ & $2.27(0.71-7.28)$ & $1.91(0.17)$ \\
\hline
\end{tabular}

Notes: $N$, number of participants in each category; $n(\%)$, number and unweighted HIV prevalence for each category; $(\%)_{\mathrm{W}}$, weighted HIV prevalence for each category; PRR $\mathrm{W}_{\mathrm{W}}$, weighted prevalence rate ratio; CI, confidence interval; CAPS, psychosocial care center, SMI, schizophrenia, bipolar disorders, depression with psychotic symptoms.

treatment is expected to absorb the patient population, yet many remain engaged in treatment without ever achieving stable housing (Angelino, 2008). Studies from developed countries of HIV-infection rates among homeless psychiatric populations had small and/or nonrepresentative samples. Nonetheless, US data show HIV seroprevalence among homeless, substance-using persons with mental illness, of $12 \%$ (Rahav, Nuttbrock, Rivera, \& Link, 1998) and a rate of $6.4 \%$ among homeless psychiatric inpatients without primary SUDs (Empfield et al., 1993). Besides psychosocial services, interventions for street youth, and targeting HIV prevention, substance use and psychiatric disorders are required.
In our study, sexual violence was an independent predictor of HIV infection. Numerous studies have shown positive associations between being at risk for or having acquired HIV infection and being a victim of sexual violence (Andersson, Cockcroft, \& Shea, 2008). A host of factors appear to mediate this relationship including early sexual debut, psychiatric hospitalization, STD history, and illicit drug use, among others (Andersson et al., 2008; Oliveira, Machado, \& Guimarães, 2012).

The association of HIV infection with previous HIV testing is of individual and public health concern. As concerning is that STD history conferred a three-fold increase in risk for HIV infection in our sample. 
Table 3. Multivariate analysis of HIV seroprevalence, PESSOAS project 2006-2007 $(n=2237)$.

\begin{tabular}{llc}
\hline Characteristics & PRR $_{\mathrm{W}}(95 \% \mathrm{CI})$ & $p$-value \\
\hline History of homelessness & $3.17(1.50-6.70)$ & $<0.01$ \\
History of STDs & $3.16(1.39-7.19)$ & $<0.01$ \\
Age in the first sexual & $9.76(1.55-61.47)$ & 0.02 \\
$\quad$ intercourse $(<18$ years old) & & \\
Sexual violence & $2.56(1.21-5.40)$ & 0.01 \\
Previous HIV testing & $6.47(2.56-16.32)$ & $<0.01$ \\
Self-perceived risk of HIV & & \\
$\quad$ Low & 1.0 & \\
$\quad$ Did not know & $2.72(1.02-7.52)$ & 0.046 \\
$\quad$ High & $3.66(1.42-9.42)$ & $<0.01$ \\
\hline
\end{tabular}

Notes: $\mathrm{PRR}_{\mathrm{W}}$, weighted prevalence rate ratio; $\mathrm{CI}$, confidence interval.

Although, HIV testing is a critical gateway to care, it is not a routine procedure in mental health services in Brazil; only patients thought to be at high risk of infection are tested. In our study, like in most, only $27 \%$ of the sample had prior HIV testing (Melo et al. 2011). Under-testing in this population has been demonstrated and reasons may include individual choice, fear, stigma associated with positive results, and poor or no availability of HIV testing in mental health treatment settings (Aguiar \& Iriart, 2012; Centers for Disease Control and Prevention (CDC), 2003; Mimiaga, Goldhammer, Belanoff, Tetu, \& Mayer, 2007; Senn \& Carey, 2009). Referral for treatment is poorly established for this population (Melo, Acurcio, Cherchiglia, Veloso, \& Guimarães, 2007). Public health benefits accrue because antiretroviral therapy reduces infectiousness and knowledge of infection status motivates risk reduction (Senn \& Carey, 2009).

It is not surprising that perception of being at higher HIV risk was also independently associated with HIV infection in our study. This may represent an accurate understanding of one's risk, but is then of concern that those who were not able to assess their own risk were also at increased risk of HIV infection. Lack of access to testing and treatment must be examined in more detail given the likelihood that referrals between mental health and medical care facilities may not be well navigated by those with psychiatric disorders, those with low income who cannot afford to travel for regular care, and those whose health care providers may not deem them ready or appropriate for intensive STD/HIV treatment and followup. The effective integration of STD treatment and HIV prevention and care programs for patients with mental illness is long overdue. Structural health care system improvements have been successful to screen, diagnose, perform contact tracing, and treat STDs, including HIV infection.
Prevention programs for high-risk persons, like commercial sex workers, injection drug users, migrant laborers, clients of sex workers, and men who have sex with men are designed with a strategic focus toward risk and harm reduction (Sahasrabuddhe \& Vermund, 2007), yet to date such strategies have not widely been put into practice for psychiatric patients despite the evidence that compromised mental health is linked to high-risk sex, diminished sexual health, substance use, homelessness, and sexual violence (Erbelding, Hutton, Zenilman, Hunt, \& Lyketsos, 2004).

There are limitations to our study. There was a higher participation of patients recruited in hospitals, but we do not think this has biased the results, since the distribution of patients according to type of care (64\% for CAPS and $36 \%$ for hospitals) was similar to the national distribution ( $62 \%$ for CAPS and $38 \%$ for hospitals), as expected by our sampling size design. Furthermore, the estimates were weighted according to sizes of centers, minimizing within cluster correlation. We relied on chart review to obtain data on psychiatric diagnoses as registered by psychiatrists within the treatment system. We could not fully examine the association of psychiatric diagnoses or symptoms to HIV seropositivity and further studies are still needed. We should also note that clinics treating primary SUDs were excluded from the study, potentially underestimating the proportion of SUD. However, we intentionally aimed at obtaining a wider representation of adult patients with mental illness, and the distribution of diagnoses is similar to the general Brazilian psychiatric populations under care. Furthermore, the cross-sectional design of our study does not allow direct causal inference, and, as shown, the association between elevated levels of mental health symptoms and elevated risky sexual behavior may not hold over time (Comulada et al., 2010). Finally, because the event was rare considerations of statistical power should be noted, although logbinomial regression is a sound and efficient method for estimating prevalence rate ratios.

In conclusion, this national cross-sectional study among adults with mental illness in Brazil found correlates of HIV infection which reflected marginalized living circumstances (history of homelessness, reporting a sexually transmitted disease, history of sexual violence, and early sexual debut) as well as HIV testing histories that may not be unique to those with mental illness but nonetheless may be targeted by the mental health care system as points of entry for HIV prevention.

\section{Acknowledgments}

This work was carried out by the Federal University of Minas Gerais with technical and financial support of the Ministry of Health/Secretariat of Health Surveillance/Department of STD, 
AIDS and Viral Hepatitis through the Project of International Technical Cooperation 914/BRA/1101 between the Brazilian Government and the United Nations Educational, Scientific and Cultural Organization, UNESCO.

\section{References}

Aguiar, M. M., \& Iriart, J. A. B. (2012). Significados e práticas de saúde e doença entre a população em situação de rua em Salvador, Bahia, Brasil [Meanings and practices associated with health and illness among the homeless in Salvador, Bahia State, Brazil]. Cadernos de Saúde Pública, 28, 115124. doi:10.1590/S0102-311X2012000100012

Andersson, N., Cockcroft, A., \& Shea, B. (2008). Genderbased violence and HIV: Relevance for HIV prevention in hyperendemic countries of southern Africa. AIDS, 22(suppl. 4), S73-S86. doi:10.1097/01.aids.0000341778. 73038.86

Angelino, A. F. (2008). Impact of psychiatric disorders on the HIV epidemic. Topics in HIV Medicine, 16(2), 99-103. Retrieved from http://www.iasusa.org/sites/default/files/tam/ 16-2-99.pdf

Brazil, Ministério da Saúde. (2011). Boletim Epidemiológico de DST/AIDS (2012). Brazil, Ministry of Health. AIDS/STD Epidemiological Data. Retrieved from http://www.aids.gov. br/publicacao/2011/boletim_epidemiologico_2011

Carey, M. P., Carey, K. B., Maisto, S. A., Gordon, C. M., \& Vanable, P. A. (2001). Prevalence and correlates of sexual activity and HIV-related risk behavior among psychiatric outpatients. Journal of Consulting and Clinical Psychology, 69(5), 846-850. doi:10.1037/0022-006X.69.5.846

Carey, M. P., Ravi, V., Chandra, P. S., Desai, A., \& Neal, D. J. (2007). Prevalence of HIV, hepatitis B, syphilis, and chlamydia among adults seeking treatment for a mental disorder in southern India. AIDS Behavior, 11, 289-297. doi:10.1007/s10461-006-9134-2

Centers for Disease Control and Prevention (CDC). (2003). HIV/AIDS special surveillance report: HIV testing survey, 2000. Atlanta, GA: US Department of Health and Human Services.

Collins, P. Y., Holman, A. R., Freeman, M. C., \& Patel, V. (2006). What is the relevance of mental health to HIV/ AIDS care and treatment programs in developing countries? A systematic review. AIDS, 20, 1571-1582. doi:10.1097/01.aids.0000238402.70379.d4

Comulada, W. S., Rotheram-Borus, M. J., Pequegnat, W., Weiss, R. E., Desmond, K A., Arnold, E. M., ... Chesney, M. A. (2010). Relationships over time between mental health symptoms and transmission risk among persons living with HIV. Psychology of Addictive Behaviors, 24(1), 109-118. doi:10.1037/a0018190

Cournos, F., Empfield, M., Horwath, E., McKinnon, K., Meyer, I., Schrage, H., ... Agosin, B. (1991). HIV seroprevalence among patients admitted to two psychiatric hospitals. American Journal of Psychiatry, 148(9), 1225-1230. Retrieved from http://ajp.psychiatryonline.org/article.aspx? articleid $=167935$

Cournos, F., Guimarães, M. D., \& Wainberg, M. L. (2012). HIV/AIDS and serious mental illness: A risky conclusion. Psychiatric Services, 63(12), 1261. doi:10.1176/appi.ps. 631202

Cournos, F., \& McKinnon, K. (1997). HIV seroprevalence among people with severe mental illness in the United States: A critical review. Clinical Psychology Review, 17, 259-269. doi:10.1016/S0272-7358(97)00018-4
Direitos Humanos. (2005) [Human Rights (2005)]. Fórum Nacional de Direitos Humanos [National human rights forum]. Retrieved from http://www.direitos.org.br/ index.php?option $=$ com_content $\&$ task $=$ view\&id $=701 \&$ Itemid $=2$.

Empfield, M., Cournos, F., Meyer, I., McKinnon, K., Horwath, E., Silver, M., ... Herman, R. (1993). HIV seroprevalence among homeless patients admitted to a psychiatric inpatient unit. American Journal of Psychiatry, 150(1), 47-52. Retrieved from http://ajp.psychiatryonline.org/article.aspx? articleid $=169171$

Erbelding, E. J., Hutton, H. E., Zenilman, J. M., Hunt, W. P., \& Lyketsos, C. G. (2004). The prevalence of psychiatric disorders in sexually transmitted disease clinic patients and their association with sexually transmitted disease risk. Sexually Transmitted Diseases, 31(1), 8-12. doi:10.1097/ 01.OLQ.0000105326.57324.6F

Guimarães, M. D. C., Campos, L. N., Melo, A. P. S., Carmo, R. A., Machado, C. J., \& Acurcio, F. A. (2009). Prevalence of HIV, syphilis, hepatitis B and C among adults with chronic mental illness: A multicenter study in Brazil. Revista Brasileira de Psiquiatria, 31(1), 43-47. doi:10.1590/ S1516-44462009000100011

Guimarães, M. D. C., McKinnon, K., Campos, L. N., Melo, A. P. S., \& Wainberg, M. L. (2010). HIV risk behavior of psychiatric patients with mental illness: A sample of Brazilian patients. Revista Brasileira de Psiquiatria, 32(4), 351-360. doi:10.1590/S1516-44462010000400007

Guimarães, M. D. C., Oliveira, H. N., Campos, L. N., Santos, C. A., Gomes, C. E. R., Oliveira, S. B., ... Machado, C. J. (2008). Reliability and validity of a questionnaire on vulnerability to sexually transmitted infections among adults with chronic mental illness - PESSOAS project. Revista Brasileira de Psiquiatria, 30(1), 55-59. doi:10.1590/S151644462008005000005

Henning, M. P., Krüger, C., \& Fletcher, L. (2012). HIV seropositivity in recently admitted and long-term psychiatric inpatients: Prevalence and diagnostic profile. African Journal of Psychiatry, 15(1), 47-53. doi:10.4314/ajpsy.v15i1.7

Himelhoch, S., McCarthy, J. F., Ganoczy, D., Medoff, D., Dixon, L. B., \& Blow, F. C. (2007). Understanding associations between serious mental illness and HIV among patients in the VA health system. Psychiatric Services, 58, 1165-1172. doi:10.1176/appi.ps.58.9.1165

Loue, S., Sajatovic, M., \& Mendez, N. (2011). Substance use and HIV risk in a sample of severely mentally Ill Puerto Rican women. Journal of Immigrant and Minority Health, 13(4), 681-689. doi:10.1007/s10903-011-9452-y

Meade, C., \& Sikkema, K. J. (2007). Psychiatric and psychosocial correlates of sexual risk behavior among adults with severe mental illness. Community Mental Health Journal, 43, 153-169. doi:10.1007/s10597-006-9071-6

Melo, A. P. S., Acurcio, F. A., Cherchiglia, M. L., Veloso, C. C. G., \& Guimarães, M. D. C. (2007). Evaluation of mental health services: Care and prevention of sexually transmitted diseases within PESSOAS project context. Revista Médica de Minas Gerais, 17(suppl. 4), S240-S248.

Melo, A. P. S., César, C. C., Acurcio, F. A., Campos, L. N., Ceccato, M. G. B., Wainberg, M. L., ... Guimarães, M. D. C. (2010). Individual and institutional determinants of AIDS knowledge among psychiatric patients in a multicenter study in Brazil. Community Mental Health Journal, 46, 505-516. doi:10.1007/s10597-010-9303-7

Melo, A. P. S., Machado, C. J., \& Guimarães, M. D. C. (2011). HIV testing among adults with chronic mental illness in 
Brazil. Journal of Acquired Immune Deficiency Syndrome, 57, S157-S163. doi:10.1097/QAI.0b013e31821e9be1

Mimiaga, M. J., Goldhammer, H., Belanoff, C., Tetu, A. M., \& Mayer, K. H. (2007). Men who have sex with men: Perceptions about sexual risk, HIV and sexually transmitted disease testing, and provider communication. Sexually Transmitted Diseases, 34(2), 113-119. doi:10.1097/01. olq.0000225327.13214.bf

Ngwena, J. (2011). HIV/AIDS awareness in those diagnosed with mental illness. Journal of Psychiatric and Mental Health Nursing, 18(3), 213-220. doi:10.1111/j.13652850.2010.01657.x

Oliveira, H. N., Machado, C. J., \& Guimarães, M. D. C. (2012). Factors associated with self-report of sexual violence against men and women with mental disorders in Brazil. Social Psychiatry and Psychiatric Epidemiology, 47, 1567-1579. doi:10.1007/s00127-011-0463-8

Paiva, V., Calazans, G., Venturi, G., \& Dias, R. (2008). Age and condom use at first sexual intercourse of Brazilian adolescents. Revista de Saúde Publica, 42(S1), 45-53. doi:10.1590/S0034-89102008000800007

Petersen, M. R., \& Deddens, J. A. (2008). A comparison of two methods for estimating prevalence ratios. BMC Medical Research Methodology, 8, 9. doi:10.1186/1471-2288-8-9

Pirl, W. F., Greer, J. A., Weissgarber, C., Liverant, G., \& Safren, S. A. (2005). Screening for infectious diseases among patients in a state psychiatric hospital. Psychiatric Services, 6, 1614-1616. doi:10.1176/appi.ps.56.12.1614

Prince, J. D., Walkup, J., Akincigil, A., Amin, S., \& Crystal, S. (2012). Serious Mental illness and risk of new HIV/AIDS diagnoses: An analysis of medic aid beneficiaries in eight states. Psychiatric Services, 63(10). doi:10.1176/appi. ps. 201100342

Rahav, M., Nuttbrock, L., Rivera, J. J., \& Link, B. G. (1998). HIV infection risks among homeless, mentally ill, chemical misusing men. Substance Use and Misuse, 33(6), 1407-1426. doi:10.3109/10826089809062224
Rosenberg, S. D., Goodman, L. A., Osher, F. C., Swartz, M. S., Essock, S. M., Butterfield, M. I., ... Salyers, M. P. (2001). Prevalence of HIV, hepatitis B, and hepatitis C in people with severe mental illness. American Journal of Public Health, 91, 31-37. doi:10.2105/AJPH.91.1.31

Sahasrabuddhe, V. V., \& Vermund, S. H. (2007). The future of HIV prevention: STI control and circumcision interventions. Infectious Diseases Clinics of North America, 21(1), 241-xi. doi:10.1016/j.idc.2007.03.005

Santelli, J. S., Lindberg, L. D., Abma, J., McNeely, C. S., \& Resnick, M. (2000). Adolescent sexual behavior: Estimates and trends from four nationally representative surveys. Family Planning Perspectives, 32(4), 156-165. doi: $10.2307 / 2648232$

Senn, T. E., \& Carey, M. P. (2009). HIV testing among individuals with a severe mental illness: Review, suggestions for research, and clinical implications. Psychological Medicine, 39(3), 355-363. doi:10.1017/S003329170800 3930

Spiegelman, D., \& Hertzmark, E. (2005). Easy SAS calculations for risk or prevalence ratios and differences. American Journal of Epidemiology, 162(3), 199-200. doi:10.1093/aje/kwi188

Vermund, S. H. (2011). Modeling interventions to assess HIV epidemic impact in Africa. Journal of Acquired Immune Deficiency Syndrome, 58(2), 121-122. doi:10.1097/QAI. 0b013e31822ff904

Wainberg, M. L., McKinnon, K., Elkington, K. S., Mattos, P. E., Mann, C. G., Pinto, D. S., ... Cournos, F. (2008). HIV risk behaviors among outpatients with severe mental illness in Rio de Janeiro, Brazil. World Psychiatry, 7, 166172. Retrieved from http://www.ncbi.nlm.nih.gov/pmc/ articles/PMC2559926/

World Health Organization (WHO). (2004). ICD-10: International statistical classification of diseases and related health problems: Tenth revision. (2nd ed.). Geneva: WHO Press. 